\title{
Making Friends
}

Naomi Katz

When you ask students why they came to this country, the answer often comes in one word, "freedom". When you ask them what they expect to find in your classroom, the word is invariably, "conversation". The exercise described in this paper combines the two expectations.

In his small book with big ideas, Cultural Literacy for Freedom, C. A. Bowers (Elan Publishers, Inc., 1974) states

Freedom is a dimension of our consciousness, and can be viewed as existing in varying degrees, depending upon the parameters that are established by the culture and the nature of the socialization process within the culture. (p. 30)

Conversation is what inevitably ensues as the socialization process is promoted in the classroom.

The performance objective of the exercise to be described here is to steer your students to places where they might go to "make friends" with mainstream Canadians. In the process of doing this they will be introduced to the teacher's rationale for the places suggested; learn some proper approaches to the people there; be able to continue on with dialogues started on the cards they choose, express their own rationales and experiences and listen to those of other students. Each of these activities can offer opportunities for understanding, speaking, reading and writing.

\section{"Making Friends" consists of:}

- an introductory page to the first lesson,

- a set of numbered cards, and

- a list of the places on the cards.

The page headed, "To the Student" (Appendix I) is only an introductory page to the first lesson and is unnecessary for subsequent lessons. It can be used in various ways: as an oral introduction by the teacher, or as a reading exercise. Later it can be presented as a cloze.

The set of numbered cards (Appendix II) each with an orientation to a different area of a city was originally designed for Vancouver, but could be adapted to any city. On the flip side of each card is the opener to a conversation relevant to the particular place. A list of the places on the cards (Appendix III), numbered to correspond with the numbers on the 
cards is distributed to all students before the beginning of the exercise. The procedure for conducting the lesson is as follows:

As mentioned above, the page, "To the Student" introduces the concept of the lesson. The students then study the list of places they are given. From this list they mentally choose a place that appeals to them as a place to go. Not on the list is the first card, labelled "Introduction" and it is given to any outgoing student to read aloud. It says:

Many people make friends at parties. But you have to know someone to be invited. You must also know people to make your own party. What are some of the ways to make friends? Ask a fellow student.

The student thus introducing the procedure chooses a person who chooses a place from the list and announces the number. The teacher then gives the card with the corresponding number to this student, who reads it and responds in either or all of the following ways: by offering a homeland or adopted country experience, by inviting other student experiences, or, by turning the card over and using the opener to start a dialogue with another student. This last option is a role-play to the directed by the teacher. Whichever option is chosen, general discussion normally follows. Needless to say, an actual visit by the student to a place on the cards would provide further opportunities for interesting reports and class discussions. Within the classroom, there are also many possible follow-ups. In addition to the oral dialogues mentioned above, dialogues could be written, with or without the openers on the cards; idioms or grammar points on the cards could be expanded to a lesson on idioms or grammar; strategies for polite exists could be created and pronunciation emphasized in its many aspects. From the above it can be seen that all four language skills are addressed in this type of lesson, which is, essentially, an introduction to Canadian culture.

The number of places that could be used for this exercise is infinite. The newspaper is a resource for current events and many places, such as museums and art galleries, issue leaflets which could be used in the classroom. The B.C. Tourist Bureau distributed a brochure with a provincial orientation and other provinces probably do the same. You may thus find yourself adding more cards to the original set as students make their own suggestions for places to go. It is useful to be acquainted with the outside interests of your students so that you could introduce a card related to them. For example, if you know that a student plays a musical instrument, you could suggest joining a band or choir.

The following report of two lessons will illustrate how this exercise develops differently, with different students. The students in these classes were all at intermediate level English proficiency. 


\section{LESSON 1}

I read "To the Student" and students followed on their copies. A discussion followed on the meaning of the word "ethnic" and I gave the introductory card to a student who never hesitates to participate, but whose pronunciation leaves much to be desired. The class asked me to read it again and we helped him with some aspects of his pronunciation at his request. He then flipped the card over and addressed his neighbour (S2) who chose the Supermarket from her list. I gave her the corresponding card and she read it to the class. I reread it, partly to make the first student feel more comfortable and partly because this was the first lesson and I wanted to be absolutely sure that everyone understood what was happening. There were no questions when I asked for them. I then suggested that S2 turn over the card and pretend that she was in the supermarket. She turned to the neighbour on the other side and read the opener: Aren't these terrible prices? S3 said she thought the prices were fair and no dialogue ensued, so she asked the second opener: How do I cook this fish? but S3 said she didn't know. When I asked if anyone had similar experiences, S4 offered a Japanese recipe for fish with a vegetable that many in the class were not familiar with, goboh. The rest of the three-quarters of an hour was spent with her describing the vegetable and writing the recipe on the board for Yawata-maki, using goboh. The class copied it, and she said she would make it for our closing party. I made a cloze of the recipe and used it the next day. We had a great deal of fun with the word "goboh" as everyone seemed to like the sound of it. It became a catchword for the rest of the session.

There are endless possibilities for extending this introduction to the topic of food. Other recipes for ethnic food could be elicited from students; cultural factors connected with food, such as table manners are a subject for cultural comparisons as are diet and nutrition.

\section{LESSON 2}

I gave the introductory card to a different student and all understood as she read it out. She read the opener to her neighbour who chose Libraries. Her experience in a library was asking a Chinese person in Chinese about the magazines. She explained in English what she had asked and what the answer was. Another student volunteered the information that she never speaks to anyone in a library. She just chooses a book. A general discussion ensued about "making friends" in libraries and the different words for different relationships among people. This led to another student asking to take the "English Class" card. After receiving the card, he asked the opening question to another student: Have you made any Canadian 
friends? This student spoke about being invited to the wedding of a colleague of her husband and how the colleague became a friend. Another student chose Over the Back Fence. Discussion ensued about what you could say to a neighbour. "Small talk" topics led to "every other day" and similar expressions.

\section{DISCUSSION}

It is evident from the above that, whatever their original intention, the cards in this exercise can create "happenings" in the classroom. Whatever the merits of the underlying assumption of "making friends", the spontaneity that the cards induce is worth the effort of producing the exercise. This goes for the opportunity of explaining grammar and idioms as well as the promotion of discussion itself. A certain atmosphere is engendered, leading to increased communication in the classroom.

John H. Schumann (1976) examines the social factors that influence the degree to which a second language is learned. Underlying them is the assumption that social solidarity produces a good language learning situation. This can certainly be the case in the class using the "Making Friends" exercise. As far as outside the classroom is concerned, Schumann talks about the attitude of the target language group towards the second language group and vice versa. He assumes that, "If both groups positively value each other, these favourable views will be communicated to the learner and will enhance his acquisition of the target language." ( $p$. 138).

Multicultural education is a two-way street in more ways than one. Not only must we educate ourselves about the various cultures in our midst, in order to understand better the students with whom we spend so much time, but we can also go further in this process by reversing it. Encouraging our students to go out into "our world" and making it theirs, if accomplished in a non-threatening manner, can go far to make newcomers feel at home and to help them experience the freedom they are seeking.

\section{REFERENCES}

Bowers, C. A. (1974). Cultural Literacy for Freedom. Eugene, Oregon: Elan Publishers, Inc.

Schumann, John. (1976). Social distance as a factor in second language acquisition. Language Learning, 26, 135-144.

\section{THE AUTHOR}

Naomi Katz has been teaching ESL to adults for the last 17 years, and currently teaches for the Vancouver School Board's community program. She has pub- 
lished several articles in TESL Talk and TEAL Occasional Papers and served as editor of the latter journal in 1979.

\section{APPENDIX I MAKING FRIENDS}

\section{TO THE STUDENT}

The most interesting part of settling in a new country is getting to know the people. However, it is hard for those who are not fluent in the language. Nevertheless, once you have passed the beginner stage in English, there are many ways to practice the language with people you don't know. You may even make some good friends this way.

Friends are made by discovering common interests. But you must know where to go and how to behave without getting into trouble or losing a lot of money. Beware of businesses such as dating services, dance studios and travel organizations. Sometimes they set out to separate lonely people from their money, promising friends and popularity in return.

Remember, not all of them are dishonest. Some can be a lot of fun. If you're thinking of applying to one of these places, please call the Better Business Bureau first and find out about its reputation. Don't sign any contract unless you understand exactly what it says in the small print. You may get some assistance from your ethnic organization, from a translation service or, if you wish, you may bring the contract to your English class, where your teacher and other students can try to explain the English or translate it for you.

Canada welcomes thousands of immigrants a year, but their settlement is a two-way street. Both the immigrant and the native-born Canadian must help to create our free, multicultural society. This exercise will give you a few ideas on where to go to make friends with Canadians. Even if you don't make lasting friendships with all the people you talk to, the experience of making an overture or responding to one will help you with your English. 


\section{APPENDIX II \\ SAMPLE CARDS}

FRONT

\section{ENGLISH CLASSES}

School for adults who want to learn English is not the same as school for children. Children are learning to be adults in an adult world.

Adults learning English meet other adults learning English and they usually find something in common with them. Ask your teacher for information about more classes.

\section{LIBRARIES}

These are usually very quiet places. But when you are looking for a book you can start a conversation in a whisper. If you are friendly, you will often find that strangers here will be friendly too. Perhaps they will even speak your language.

8. SUPERMARKETS

You have a common interest with everybody here: food.

People often talk about prices. At the meat and fish counters you can ask other shoppers how they cook something.

\section{COIN LAUNDRIES}

While waiting for their laundry, people have time to kill. Some people read, but others would like to strike up a conversation with you.

Why don't you give them the opportunity?

\section{BACK}

3. ENGLISH CLASSES

Openers

Have you made any Canadian friends yet?

How long have you been in Canada?

4. LIBRARIES

Openers

Excuse me. Could I ask you where you got that book?

Have you ever read this author? (showing book)

(To librarian) Do you have any books in my language?

8. SUPERMARKETS

Openers

Aren't these terrible prices?

How do I cook this fish?

\section{COIN LAUNDRIES}

Openers

Excuse me. Could you show me how to operate this machine?

Do you have the time, please?

What a cute baby. What's his name? 


\section{PLACE}

1. Over the Back Fence

2. Hiking

3. English Classes

4. Libraries

5. Political Clubs

6. Beaches

7. Stanley Park Artists' Corner

8. Supermarkets

9. Coin Laundries

10. Hobby Clubs

11. Art Galleries \& Other Clubs

12. Volunteering

13. Theatres

14. Swimming

15. Shared Apartments

16. Dogs

17. Horseracing

18. Watching Sports

19. Sports \& Sport Clubs

20. Sailing

21. Ethnic Groups

22. Granville Market

23. Amateur Dramatics

24. Vancouver Aquarium in Stanley Park
STUDENT NAME
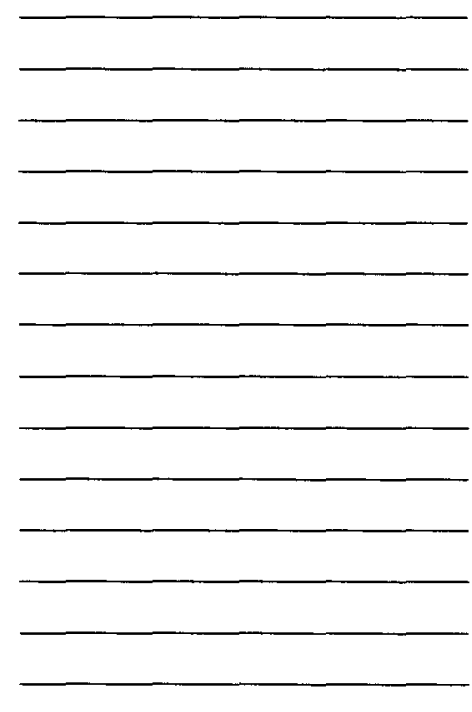